\title{
Characterization of tensile strength and impact toughness of autogenous PCGTA weldments of aeronautical steel and austenitic stainless steel
}

\author{
M. Arivarasu*, K. Devendranath Ramkumar, N. Arivazhagan \\ School of Mechanical and Building Sciences, VIT University, Vellore 632 014, India
}

Received 6 February 2015, received in revised form 26 May 2015, accepted 7 October 2015

\begin{abstract}
This research article reports the metallurgical and mechanical properties of pulsed current gas tungsten arc welded AISI 4340 and AISI 304L by autogenous technique. This article investigates the detailed structure-property relationship of the weldments using optical and scanning electron microscopy techniques. Microstructure studies corroborated the formation of martensite at the weld zone and heat affected zone of AISI 4340, which contributed to higher hardness and strength at room temperature. Tensile studies inferred that the failure occurred at the parent metal and in the weld region when operated at ambient and high-temperature conditions $\left(600^{\circ} \mathrm{C}\right)$, respectively. The average tensile strength of the welded joint was found to be $708 \mathrm{MPa}, 308 \mathrm{MPa}$ in the ambient temperature and elevated temperature, respectively. Charpy V-notch studies revealed that the average impact energy of the weldments was found to be $6.2 \mathrm{~J}$, due to the presence of martensitic structure at the weld. The outcomes of the study attested the use of autogenous- pulsed current gas tungsten arc welding, eliminating the need for filler wire, which is cost effective welding technique for joining these dissimilar metal combinations.
\end{abstract}

K e y words: aeronautical steel, austenitic stainless steel, pulsed current, microstructure, mechanical characterization

\section{Introduction}

Austenitic stainless steel, AISI 304L has a versatile range of industrial applications in thermal and nuclear power plants, aerospace and chemical industries owing to its good weldability, excellent corrosion resistance and high-temperature strength [1-3]. Since the carbon content in these grades of stainless steels is low, they are free from negative metallurgical transformations such as chromium carbide precipitation, hot cracking tendency, etc. [4]. Similarly, AISI 4340 finds its application in the design of aerospace components such as landing gear and mortar casings. Due to their high impact strength and superior fatigue properties, these steels are also preferred to manufacture components pertaining to aerospace, nuclear and defense applications [5-7]. These combinations are also being utilized in high temperature operating conditions.

Dissimilar metal welding (DMW) is one fascinat- ing field of research which offers economic viability and design flexibility. As reported by various other researchers [8-11] dissimilar metal joints of low alloy steel and stainless steel are extensively used in the power generation and nuclear sectors, where pressure vessels are made of low alloy steel and are connected to stainless steel piping systems. Despite having several advantages mentioned above, there are several setbacks reported by various other researchers while employing DMW, such as elemental migration, the formation of secondary and complex phases, partially mixed zones and vulnerability of the weld metals to liquation and hot cracking [12-14]. These problems mainly arise due to the differences in the chemical composition and thermal expansion coefficients of the metals employed. However, attempts have been carried out on the commercially practicable welding techniques such as gas tungsten arc welding, gas metal arc welding and shielded metal arc welding for solving the

*Corresponding author: tel.: +91-416-2202184; fax: +91-416-2243092; e-mail address: $\underline{\text { arivarasu.m@gmail.com }}$ 
Table 1. Chemical composition of the base metals with their $\mathrm{Cr}$ and Ni equivalent

\begin{tabular}{lccccccccccc}
\hline \multicolumn{10}{c}{ Chemical composition (wt.\%) } \\
\hline Base metal & $\mathrm{C}$ & $\mathrm{Si}$ & $\mathrm{Mn}$ & $\mathrm{Cr}$ & $\mathrm{Ni}$ & $\mathrm{Mo}$ & $\mathrm{Fe}$ & $\mathrm{Cr}_{\text {eq }}$ & $\mathrm{Ni}_{\text {eq }}$ & $\mathrm{Cr}_{\text {eq }} / \mathrm{Ni}_{\text {eq }}$ \\
\hline AISI 4340 & 0.31 & 0.23 & 0.64 & 0.98 & 1.34 & 0.23 & Bal. & 1.56 & 10.96 & 0.14 \\
AISI 304L & 0.037 & 0.46 & 0.95 & 19.14 & 8.35 & 0.17 & Bal. & 20 & 9.93 & 2.01 \\
\hline
\end{tabular}

$\mathrm{Ni}_{\text {eq }}=\% \mathrm{Ni}+(\% \mathrm{C} \times 30)+(\% \mathrm{Mn} \times 0.5)$

$\mathrm{Cr}_{\mathrm{eq}}=\% \mathrm{Cr}+\% \mathrm{Mo}+(\% \mathrm{Si} \times 0.5)+(\% \mathrm{Nb} \times 0.5)$

drawbacks above. There are some solutions adopted by the industries such as the use of the pulsed current technique, proper selection of process parameters and filler metal. Pulsed current is the modified form of conventional gas tungsten arc (GTA) welding method which enjoys several benefits regarding metallurgical and mechanical properties including lower heat input, reduced bead width and heat affected zone (HAZ), grain refinement and lower distortion [15-17]. In addition to that, the cooling rates are faster compared to the conventional GTA welding technique.

Dissimilar metal joints between low alloy steel and a stainless steel face some challenges such as hot cracking, hydrogen cracking and formation of brittle phases due to segregation, which results in premature failure of components. Researchers addressed that carbon diffusion and subsequent formation of strong metallic carbides in the weld metal and HAZ attributed to several adverse effects. The formation of these carbides substantially increased the hardness and contributed to cracking at this zone [12-14].

Ozdemir et al. [18, 19] investigated the friction welded AISI 4340 and AISI 304L joints and observed very low tensile strength of 80 and $95 \mathrm{MPa}$. The authors claimed that the formation of inter-metallic phases such as $\sigma$ and $\delta$-ferrite contributes to lower tensile strength.

Arivazhagan et al. [20] studied the effect of heat input on the microstructure and mechanical properties of GTA welds of low alloy steel and austenitic stainless steel. The authors reported that on employing high heat input, the chance of micro-segregation of alloying elements was found to be high. Also, they witnessed the depletion of chromium at the grains, which in turn deteriorated the weld mechanical properties. Several other researchers also reported the use of these dissimilar metal combinations obtained from GTAW, electron beam welding and friction welding techniques [21-24].

It is explicit from the literature that there is a huge demand for these dissimilar metal combinations in various engineering applications. As reported by various other researchers [2, 25], PCGTA welding is one of the successful welding technique employed to achieve better mechanical properties. Hence in this research work, an attempt has been made to weld this dissimilar metal combination using PCGTA welding without the aid of filler metal. Both the room and high-temperature tensile studies were performed to assess the tensile properties of the weldments. Further, Charpy V-notch impact test and hardness tests were performed in the ambient conditions to assess the mechanical properties of the weld joint.

The outcomes of the study will be highly beneficial and successfully executable in the industries employing these dissimilar metal combinations.

\section{Experimental}

\subsection{Candidate metals and welding procedure}

The chemical composition of the base metals employed in this study was examined by dry spectroscopic methods and delineated in Table 1. The dimensions of the base metals AISI 4340 and AISI 304L measuring $125 \mathrm{~mm}$ long $\times 125 \mathrm{~mm}$ wide $\times 5 \mathrm{~mm}$ thick were obtained using wire-cut electrical discharge machining (EDM) technique. The oxide layers formed during the wire cut operation were removed before the welding procedure. A square butt joint configuration was employed as shown in Fig. 1a. PCGTA welding was carried out on these dissimilar metals using Kemppi Master TIG MLS400. The thermal conductivity of AISI 304L and AISI 4340 is 16.2 and $44.5 \mathrm{~W} \mathrm{~m}^{-1} \mathrm{~K}^{-1}$, respectively, which shows that the heat dissipation in AISI 4340 would be higher. Hence, selective preheating was done on the AISI 4340 side to a temperature of $120^{\circ} \mathrm{C}$ to compensate for the thermal losses and to avoid cracking. The process parameters were selected based on the results of the iterative trials and are shown in Table 2. This study employed the use of $2 \%$ thoriated tungsten electrode, inert gas argon of $99.99 \%$ purity with a flow rate of $16 \mathrm{~L} \mathrm{~min}^{-1}$ and pulse on current of $50 \%$. The heat input, HI, calculations for the three trials were done using the formulae mentioned below [26]:

$$
\mathrm{HI}=\eta \frac{I_{\mathrm{m}} V}{S},\left(\mathrm{~J} \mathrm{~mm}^{-1}\right),
$$

where $\eta$ is the arc efficiency which is $60 \%, I_{\mathrm{m}}$ is the 
Table 2. Process parameters for autogenous PCGTAW welding of AISI 4340 and AISI 304L

\begin{tabular}{ccccccccc}
\hline Trial & $\begin{array}{c}\text { Voltage } \\
(\mathrm{V})\end{array}$ & $\begin{array}{c}\text { Peak current } \\
I_{\text {peak }}(\mathrm{A})\end{array}$ & $\begin{array}{c}\text { Base current } \\
I_{\text {base }}(\mathrm{A})\end{array}$ & $\begin{array}{c}\text { Pulse on } \\
\text { time }\end{array}$ & $\begin{array}{c}\text { Frequency } \\
(\mathrm{Hz})\end{array}$ & $\begin{array}{c}\text { Welding } \\
\text { speed } S \\
\left(\mathrm{~mm} \mathrm{~min}^{-1}\right)\end{array}$ & $\begin{array}{c}\text { Gas flow rate } \\
\left(\mathrm{L} \mathrm{min} \mathrm{min}^{-1}\right)\end{array}$ & $\begin{array}{c}\text { Max. heat } \\
\text { input } \\
\left(\mathrm{kJ} \mathrm{mm}^{-1}\right)\end{array}$ \\
\hline 1 & $12-13$ & 240 & 100 & $50 \%$ & 6 & 150 & 16 & 0.530 \\
2 & $12-13$ & 260 & 100 & $50 \%$ & 6 & 150 & 16 & 0.561 \\
3 & $13-14$ & 280 & 100 & $50 \%$ & 6 & 150 & 16 & 0.638 \\
\hline
\end{tabular}
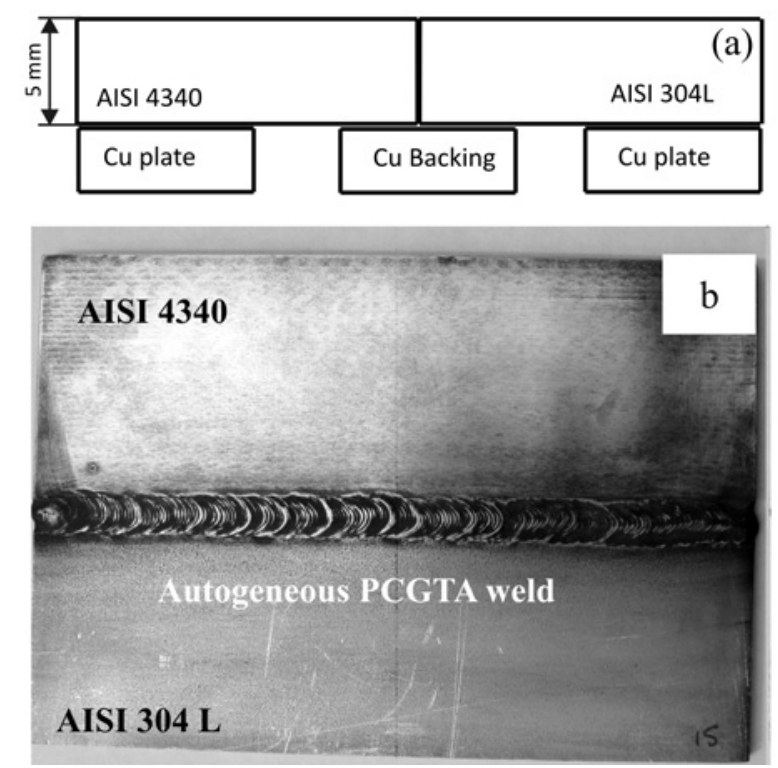

Fig. 1. Dissimilar weld joint between AISI 4340 and 304L employing autogenous PCGTA welding: (a) schematic representation of "square butt joint" configuration; (b) photograph of the as-welded joint.

mean current in (A), $V$ is the voltage at the time of welding in (V), $S$ is the welding speed in $\left(\mathrm{mm} \mathrm{s}^{-1}\right)$.

In pulsed GTAW, the mean current is considered for heat input calculation because the current is being pulsed from a higher peak value to a lower base value at a particular frequency. The mean current $I_{\mathrm{m}}[26]$ is calculated using the equation

$$
I_{\mathrm{m}}=\frac{I_{\mathrm{P}} t_{\mathrm{p}}+I_{\mathrm{b}} t_{\mathrm{b}}}{t_{\mathrm{p}}+t_{\mathrm{b}}}
$$

where $I_{\mathrm{P}}$ is the peak current, $I_{\mathrm{b}}$ is the base current, $t_{\mathrm{p}}$ is the peak current duration, and $t_{\mathrm{b}}$ is the base current duration.

\subsection{Macro- and microstructure examination}

Dissimilar joints of AISI 4340 and AISI 304L were investigated using dye penetrant test and $\gamma$-ray radiography non-destructive testing (NDT) technique to evaluate the weldment for surface and sub-surface defects, respectively. On conforming to the NDT accep- tance, the weldments were sliced to coupons of different dimensions to facilitate various metallurgical and mechanical tests.

Macro- and microstructure examination was carried out on the cross section of the weldment measuring $30 \mathrm{~mm} \times 15 \mathrm{~mm} \times 5 \mathrm{~mm}$, which covers all the zones including the base metals, weld zone and HAZ of both the parent metals. Standard metallographic procedures were employed on these coupons to reveal the microstructure at various zones of the weldments. Two percentage nital for AISI 4340 side, weld zone and a mixed acid solution containing $15 \mathrm{ml} \mathrm{HCl,} 10 \mathrm{ml}$ acetic acid, $10 \mathrm{ml}$ nitric acid for AISI 304L were used as etchants to examine the microstructures. Both optical and scanning electron microscopy techniques were adopted to understand the microstructure features of these dissimilar joints.

\subsection{Mechanical characterization of the weldments}

Mechanical properties of the weldments were ascertained by conducting various tests. Microhardness examination was carried out on the composite zone at different passes vis-à-vis cap, filler and root pass of the weldment by applying a test load of $500 \mathrm{gf}$ load for $10 \mathrm{~s}$. The measurements were recorded at regular intervals of $0.25 \mathrm{~mm}$. The tensile test was carried out both at room temperature and high-temperature conditions $\left(600^{\circ} \mathrm{C}\right)$ to assess the performance of the weldments. Room temperature transverse tensile testing specimens were prepared as per ASTM: E8/8M standard. Testing of the samples was carried out using Instron dynacell-8081 with a crosshead velocity of $2 \mathrm{~mm} \mathrm{~min}^{-1}$ to maintain a uniform strain rate of $3.3 \times 10^{-4} \mathrm{~s}^{-1}$. High-temperature tensile testing was carried out on the samples in accordance with ASTM E21-2009. Testing temperature was $600^{\circ} \mathrm{C}$ and the samples were held for $20 \mathrm{~min}$ at the elevated temperature before the load was applied.

To assess the response of the weldments to impact loading, Charpy V-notch test at room temperature $\left(24^{\circ} \mathrm{C}\right)$ was conducted on the specimens prepared as per ASTM E23-07. Both the tensile and impact studies were performed on three samples to ensure the repeatability of the results. 

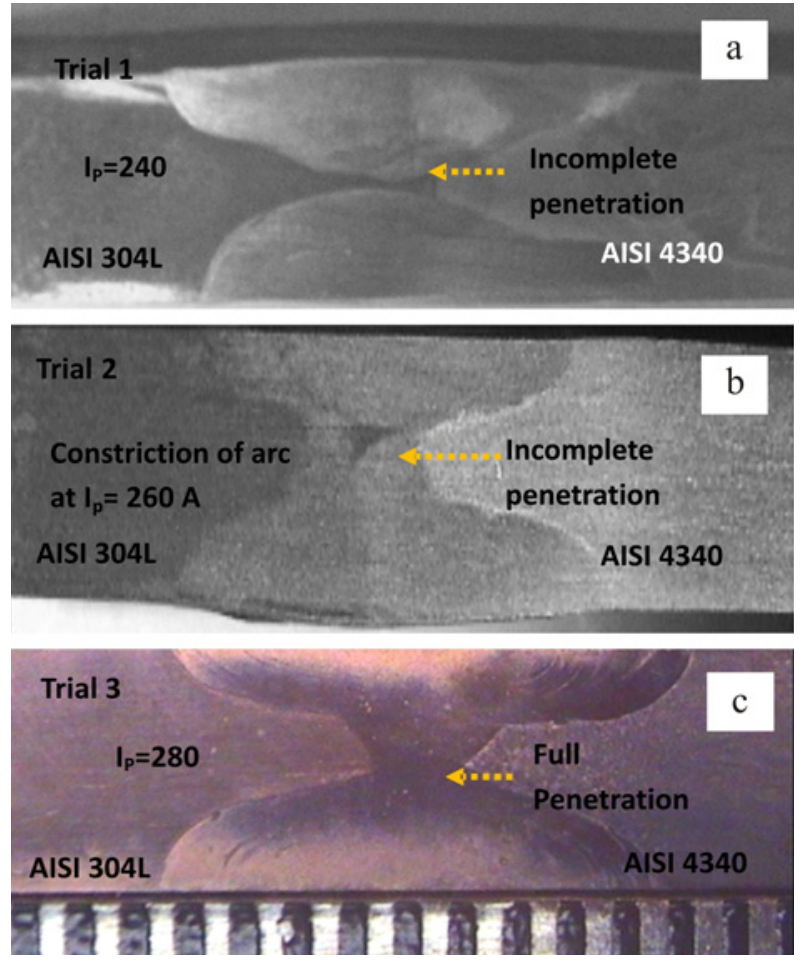

Fig. 2. The macrostructure showing the dissimilar weldments of AISI 4340 and AISI 304L (a) trial 1; (b) trial 2; (c) trial 3.

\section{Results and discussion}

\subsection{Metallurgical characterization}

\subsubsection{Macro- and microstructure examination}

Visual inspection of the as-welded samples in Fig. 1a reveals good weld bead and absence of surface defects like surface porosity, undercut, and cracks.
Macrostructure examination of the trials is represented in Figs. 2a-c. Full penetration joint in Fig. 2c with proper sidewall fusion between the parent metals could be achieved with autogenous PCGTA welding on employing the parameters of Trial 3 .

Microstructure studies revealed dense pearlite colonies present in the ferrite matrix in Fig. 3a at the parent metal of AISI 4340. The presence of twins and $\delta$-ferrite stringers running parallel to the rolling direction in the austenitic matrix is observed in AISI 304L in Fig. 3b.

The HAZ of AISI 4340 in Fig. 4a shows the formation of martensite with carbide precipitates. Whereas, delta ferrite clusters are observed at the partially melted zone of AISI 304L as shown in Fig. 4b. These delta ferrite clusters have beneficial effects like betterelevated temperature ductility and lower thermal expansion coefficient than the austenite [27]. This allows relaxation of thermal stresses and less thermal contraction, thereby preventing the liquation cracking at the HAZ of AISI 304L. The weld zone microstructure in Fig. 4c is observed to have martensite with finely dispersed carbides. The formation of martensite at the fusion zone and HAZ of AISI 4340 could be substantiated to the pearlite to martensite transformation, due to weld thermal cycle [2]. Arivazhagan et al. [13] and Ozdemir et al. [18] reported that the factors such as temperature gradient and physical constraints played important roles in altering the microstructures. During welding, high temperature (above upper critical temperature, $\mathrm{AC}_{3}$ ) is attained in the weld zone and the HAZ of AISI 4340 steel. The composition in the weld zone and HAZ of AISI 4340 favours the austenite formation at this high temperature. According to the literature [15], [16], pulsed current results in reduced heat input and also higher cooling rate in the fusion zone. Further, the thermal conductivity of the parent material AISI 4340 is high, resulting in higher tempe-

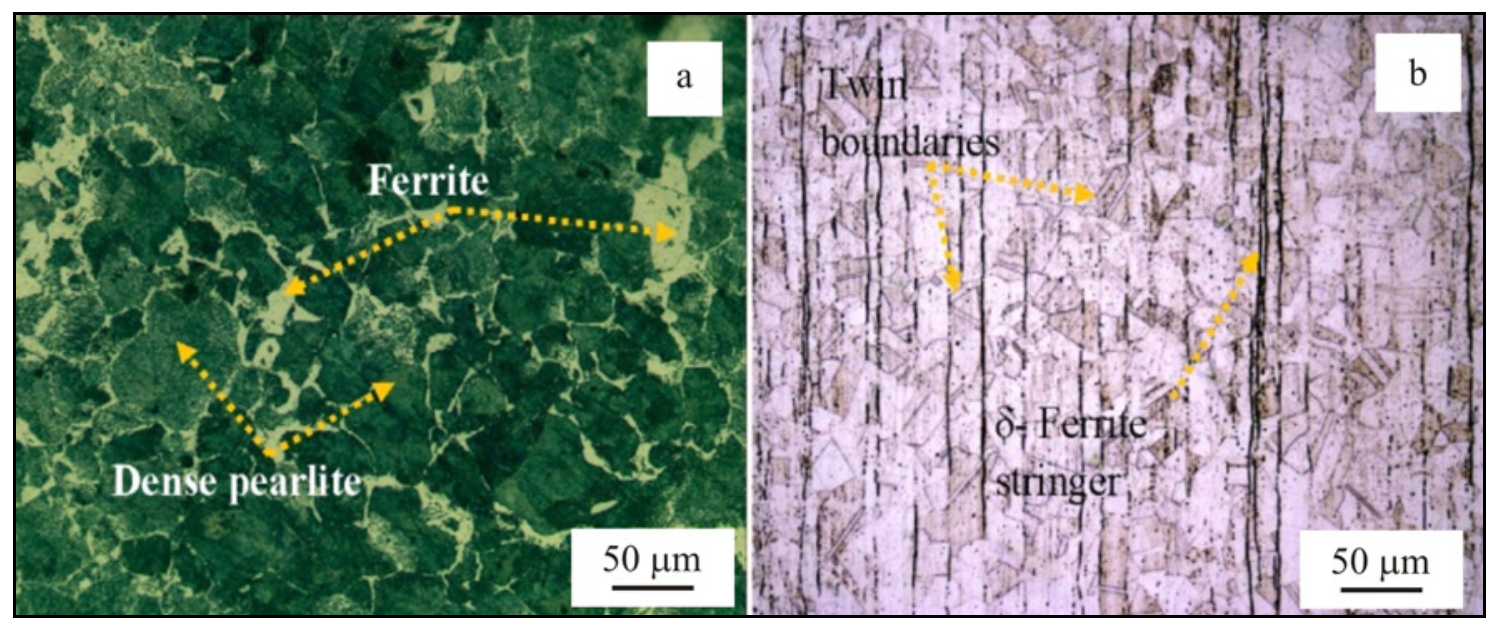

Fig. 3. The microstructure of the base metals: (a) AISI 4340; (b) AISI 304L. 

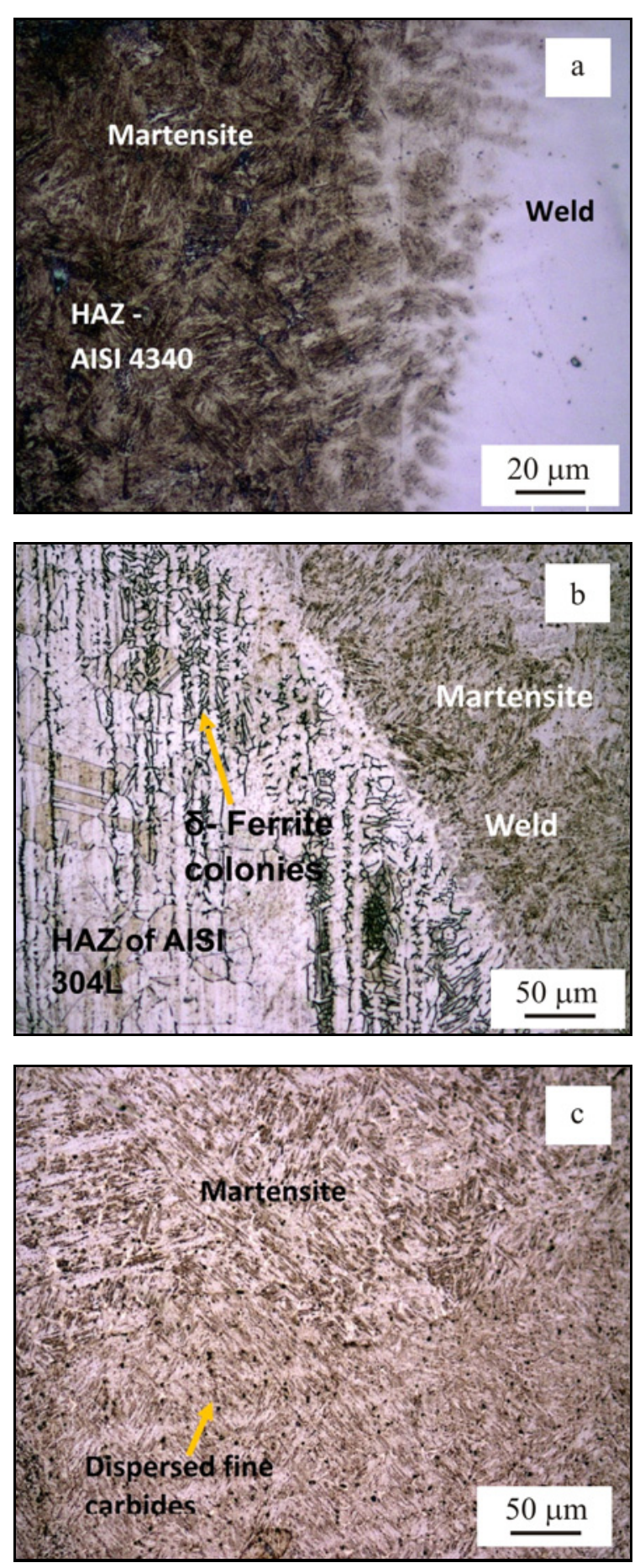

Fig. 4. Interface and weld microstructures of the dissimilar weldments showing (a) HAZ - weld of AISI 4340; (b) HAZ - weld of AISI 304L and (c) weld zone.

rature gradient between the weld and the AISI 4340 parent material, which accelerates the cooling rate in the weld metal and HAZ of AISI 4340. This condition favours for the transformation of the already formed austenite in the weld zone and HAZ of AISI 4340, to martensite. Also, enriched amounts of carbon at the weld and the low alloy steel side with a higher cooling rate resulted in the formation of dispersed carbides at these zones.

\subsubsection{Scanning electron microscopy and} energy-dispersive $X$-ray spectroscopic analysis

Scanning electron microscopic (SEM) micrographs and energy-dispersive X-ray spectroscopic (EDS) analysis were carried out on the cross-sectioned coupon of the weldment. SEM/EDS at the interface between AISI 304L and the weld is represented in Fig. 5a and the interface between the weld and AISI 4340 is represented in Fig. 5b. The line mapping shows the composition of various elements across the weldments. It is evident that an element Fe has gradually migrated from AISI 4340 to AISI 304L side. Cr and Ni have also gradually migrated from AISI 304L to the weld zone. EDS quantitative point analysis in Fig. 6a,b was also carried out to infer the presence of elements at various locations of the weldments. The analysis carried out in the weld zone adjacent to AISI 304L side shows the presence of $9.88 \% \mathrm{Cr}$ and $4.31 \% \mathrm{Ni}$. Similarly, the presence of $6.8 \% \mathrm{Cr}$ and $3.5 \% \mathrm{Ni}$ is observed at the weld zone adjacent to AISI 4340. The elemental composition observed in both the weld zones shows that $\mathrm{Cr} \%$ is predominant than the $\mathrm{Ni} \%$. Also, the $\mathrm{Cr}_{\text {eq }} / \mathrm{Ni}_{\text {eq }}$ ratio is found to be 0.16 and 0.10 at the weld zone $\mathrm{Z} 1$ and $\mathrm{Z} 2$, respectively. This is similar to the AISI 4340 parent metal $\mathrm{Cr}_{\text {eq }} / \mathrm{Ni}_{\text {eq }}$ ratio. The observed chemical composition and the $\mathrm{Cr}_{\text {eq }} / \mathrm{Ni}_{\text {eq }}$ ratio suggest that the weld zone could have the conditions favouring the martensite structure.

\subsection{Mechanical characterization}

\subsubsection{Hardness measurements}

The hardness profile of the dissimilar weldment is shown in Fig. 7 and the average hardness values of the dissimilar joint are represented in Table 3. Microhardness measurements inferred that the average hardness of the weld zone was found to be $502 \mathrm{HV}$ and the average hardness at the HAZ of AISI 4340 was found to be $544 \mathrm{HV}$. Conversely, hardness at the HAZ of AISI 304L was found to be $216 \mathrm{HV}$. This higher hardness clearly envisaged the formation of martensitic phase and carbides in the weld zone and the HAZ of AISI 4340 , the difference in the average hardness values in these zones could be attributed to the difference in the carbon content. It is evident from the hardness plots that the hardness at the weld zone and HAZ of AISI 4340 is found to be greater as compared to other zones of the weldments and it is suggested that these zones are the strongest part of the joint. The tensile results also support the discussion, as the tensile failure took place in the parent metal AISI 304L. 

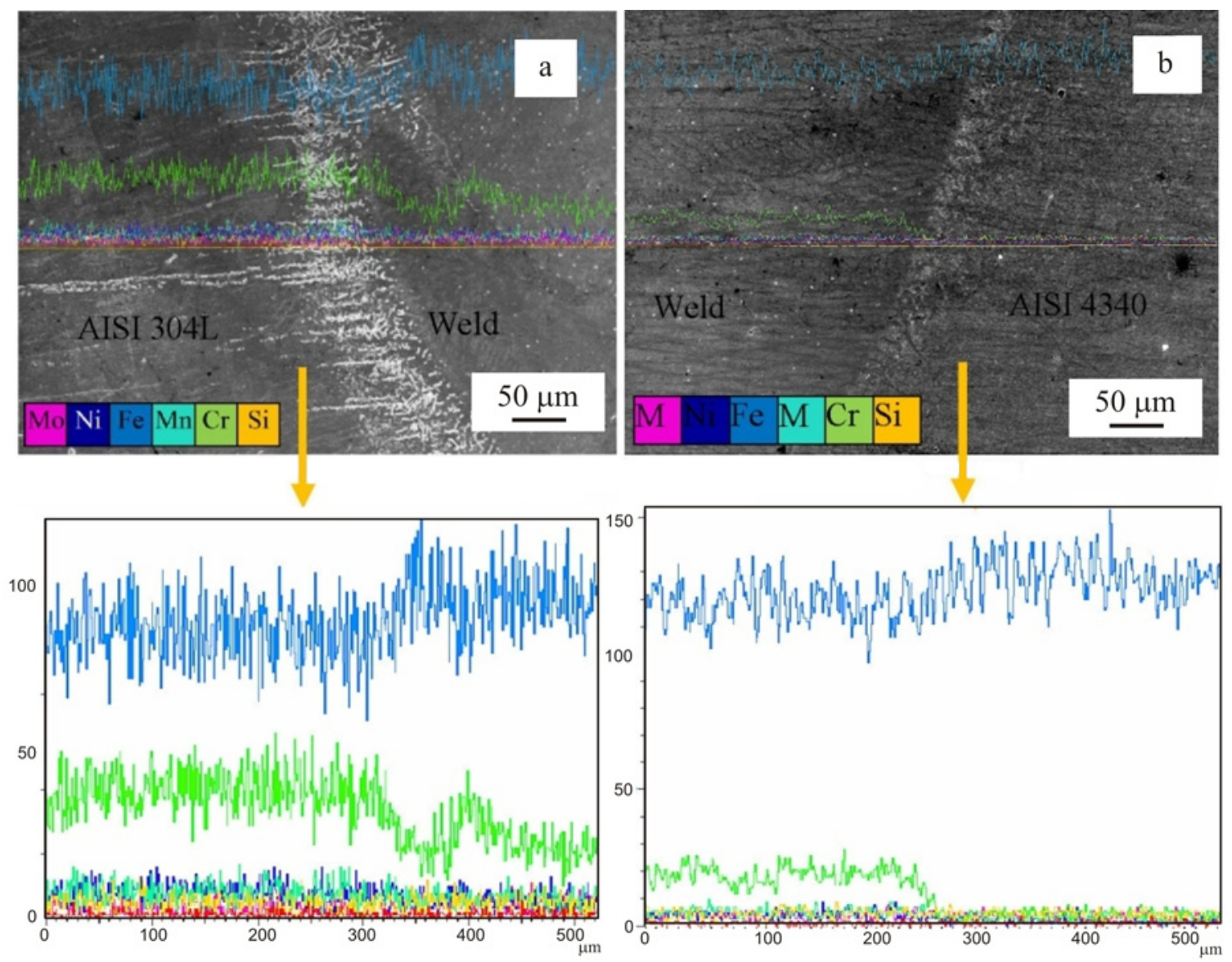

Fig. 5. EDS line mapping analysis on the dissimilar weldments of AISI 4340 and AISI 304L: (a) interface between AISI 304L and the weld; (b) interface between the weld and AISI 4340.

Ta ble 3. Hardness values at different locations of the dissimilar joint between AISI 4340 and AISI 304L

Vickers microhardness value, $\mathrm{HV}$

\begin{tabular}{ccc}
\hline HAZ of AISI 4340 & Weld ( Fusion zone) & HAZ of AISI 304L \\
\hline $544 \pm 13$ & $502 \pm 37$ & $216 \pm 4$ \\
\hline
\end{tabular}

\subsubsection{Tensile test at room and high-temperature conditions}

Tensile test results at the room temperature conditions in Fig. 8a clearly depicted that the fracture occurred in the parent metal AISI 304L in all the trials. The average tensile strength of these dissimilar weldments is $708.5 \mathrm{MPa}$, with a considerable amount of ductility as depicted from the SEM fractography results shown in Fig. 8b. The surface fractography in Fig. 8b exhibited predominately dimpled rupture features without any preferential fracture path. Also, they show fibrous network intimating that the mode of failure is ductile. The average elongation of the dissimilar weld joint is found to be $12.5 \mathrm{~mm}$. As reported by Arivazhagan et al. [28], these dissimilar metal joints are operated in high-temperature conditions. Hence, it is reckoned to perform high-temperature tensile studies at $600^{\circ} \mathrm{C}$ to assess the performance of these dissimilar weldments in service conditions. The tensile study shows that the fracture occurred at the weld zone in Fig. 9a and the ultimate tensile strength is reported to be $308 \mathrm{MPa}$. SEM fractography results in Fig. 9b show the presence of coarse voids and dimples in the ductile tearing ridges in the high-temperature conditions. The average tensile properties of the dissimilar joint are shown in Table 4.

The tensile results were in concordance with the hardness data and microstructure. The formation of martensite in the weld zone and HAZ of AISI 4340 contributed to better strength and hardness, suggesting that the fracture would not be experienced in 

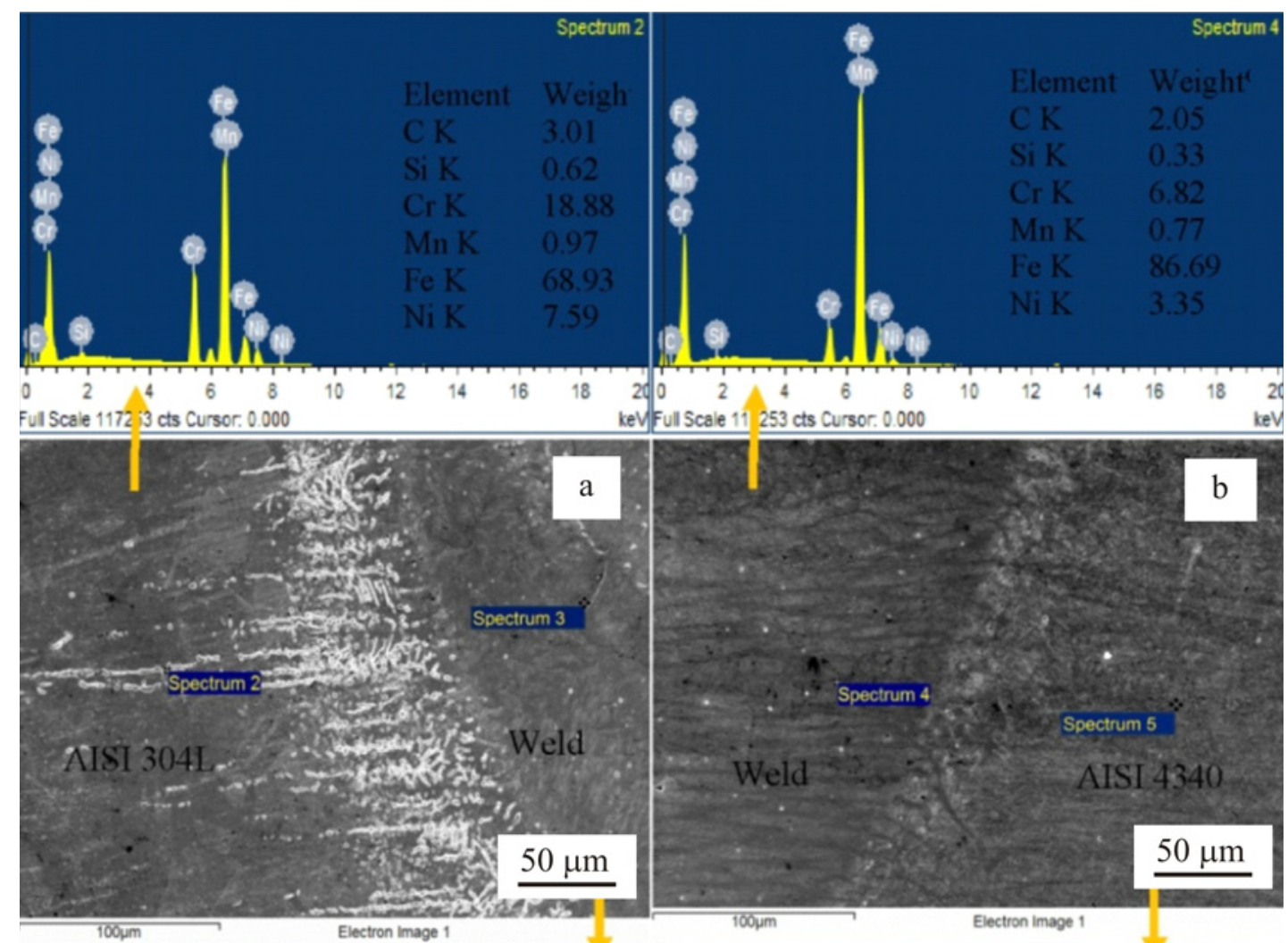

keV
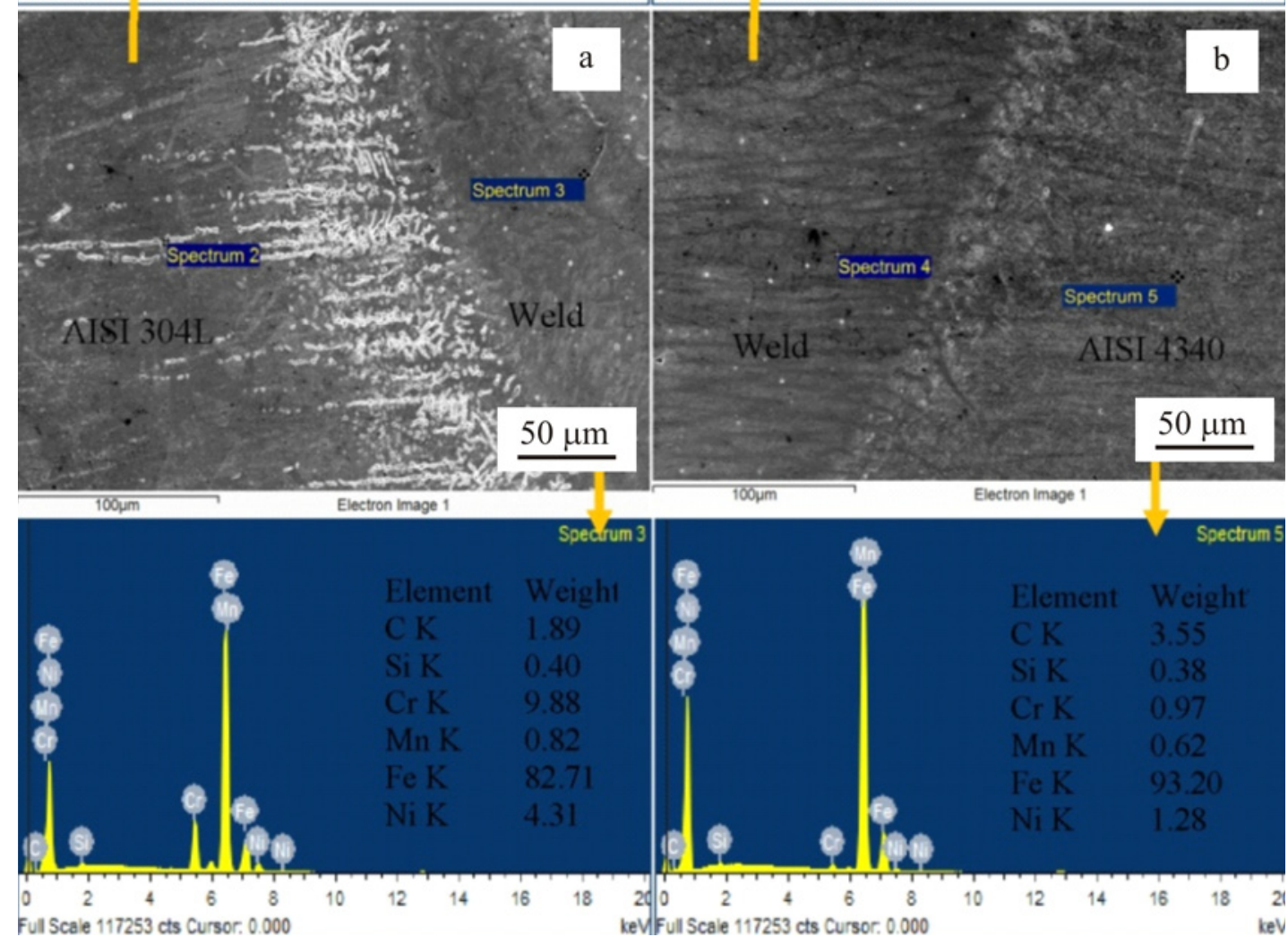

Full Scale 117253 cts Cursor: 0.000

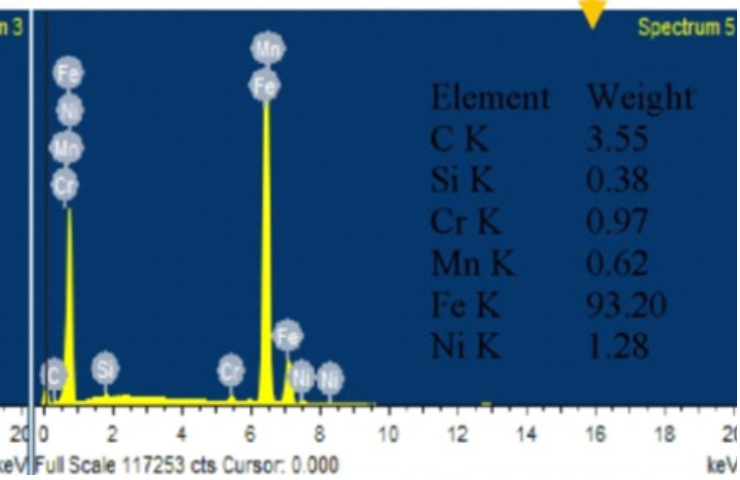

Fig. 6. SEM/EDS point analysis on the dissimilar weldments of AISI 4340 and AISI 304L: (a) interface between AISI 304L and the weld; (b) interface between the weld and AISI 4340.

Ta b l e 4. Room temperature and high-temperature tensile properties of the dissimilar joint between AISI 4340 and AISI $304 \mathrm{~L}$

\begin{tabular}{|c|c|c|c|}
\hline \multirow{2}{*}{ Property } & \multirow{2}{*}{ Unit } & Room temperature & High-temperature conditions $\left(600^{\circ} \mathrm{C}\right)$ \\
\hline & & Avg. (SD) & Avg. (SD) \\
\hline Ductility & $(\%)$ & $38.75 \pm 2.0$ & $7.90 \pm 0.08$ \\
\hline Ultimate tensile strength & $(\mathrm{MPa})$ & $708.5 \pm 33$ & $308 \pm 5.60$ \\
\hline Fracture location & & Parent metal of AISI $304 \mathrm{~L}$ & Weld zone \\
\hline
\end{tabular}

these zones. Also, the HAZ of AISI 304L exhibited an agglomeration of delta ferrite stringers with coarse grains. These delta ferrite colonies act as a barrier for deformation mechanism. As the parent metal of AISI 304L offered lower hardness values, the tensile fracture is experienced at this zone.

In room temperature tensile testing, during loading, the primary deformation is facilitated due to movement of dislocations by a glide. With the presence of the finer martensitic structure, dislocation move- 


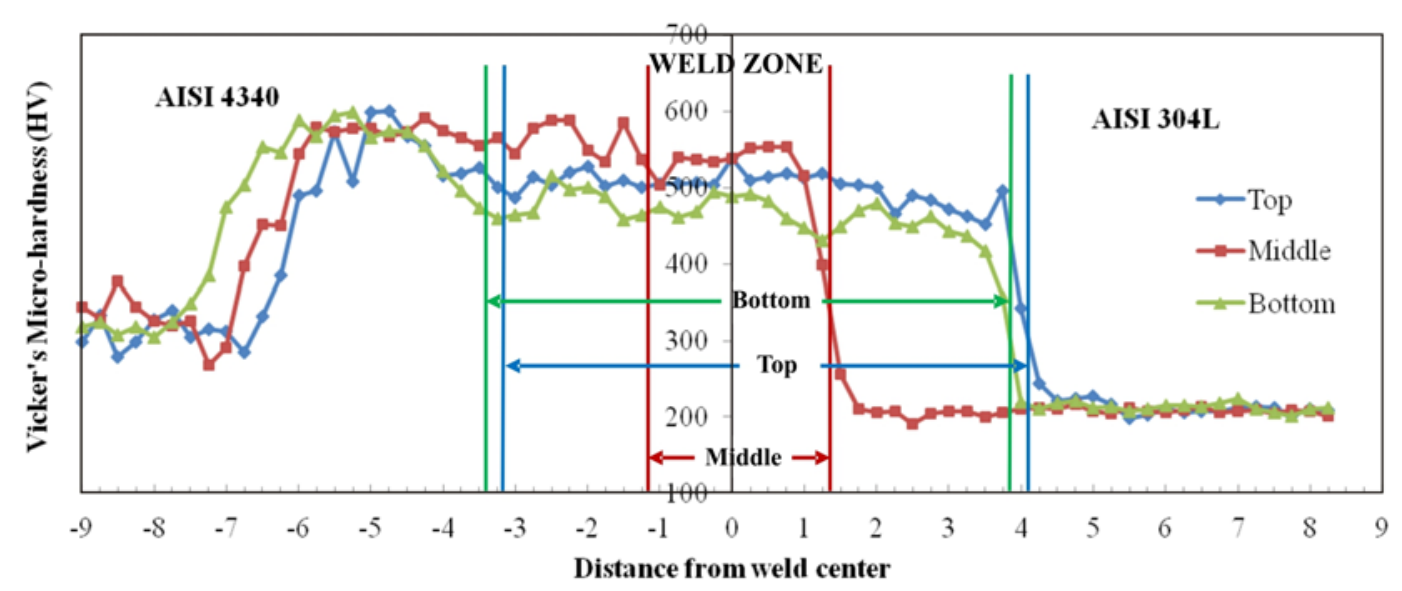

Fig. 7. Vickers microhardness measurements at different zones of the dissimilar weldments of AISI 4340 and AISI 304L.
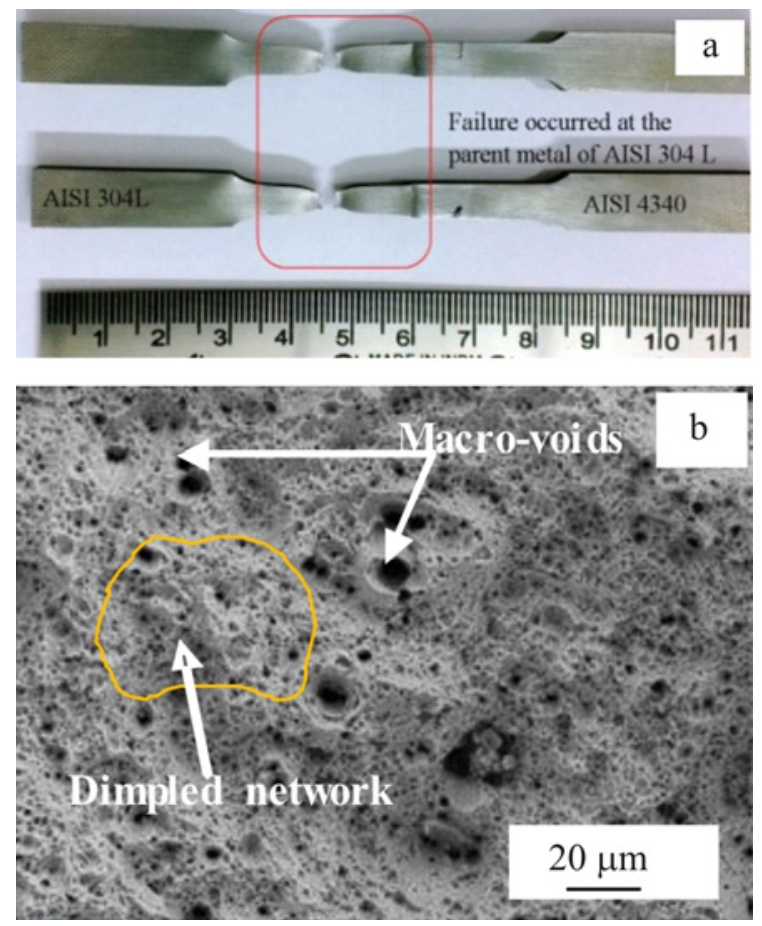

Fig. 8. (a) Tensile tested specimens of dissimilar weldments showing the fracture occurred at the parent metal of AISI 304L; (b) SEM fractography showing the presence of dimples and micro-voids on the fractured surface.

ment is restricted at the grain boundaries and eventually a huge amount of energy is required to break up the dislocation pile-up. It is thus evident that the finer martensitic grains in the weld zone contributed to better strength at the room temperature.

At elevated temperatures, the mobility of atoms increases due to active diffusion controlled mechanisms. Further, the dislocation climb is a thermally activated process that causes greater mobility of dislocations out of glide planes by interaction with vacancies. The formation of new glide systems and increased dislocation
Ta ble 5. Impact toughness data at room temperature conditions

\begin{tabular}{lc}
\hline Description & Average impact toughness $(\mathrm{J})$ \\
\hline Parent metal AISI 4340 & $12 \pm 1$ \\
Parent metal AISI 304L & $68 \pm 1$ \\
Weld & $6 \pm 1$ \\
\hline
\end{tabular}

mobility assists the glide to a larger extent thereby impoverishing the tensile strength at the elevated temperatures [29].

Fine-grained martensitic structure in the weld zone has high dislocation density which exhibits higher yield strength at lower temperature, but at the elevated temperature, due to enhanced rate of void formation and increased dislocation mobility, results in reduced tensile strength of this dissimilar weld joint [30-32].

\subsubsection{Impact test}

It is important to note the response of the dissimilar welds to the impact loading conditions to test its survivability in service conditions. Hence, Charpy Vnotch impact test was carried out on these dissimilar weldments in Fig. 10a. The impact toughness values of the weldment and the employed base metals are represented in Table 5. It was inferred from the results that the impact toughness of the dissimilar weldments in the as-welded condition is found to be lower $(6 \mathrm{~J})$. As discussed earlier, due to the formation of high carbon martensite in the weld zone (as supported by microhardness values and impact energies), the observed energy was low. Further, SEM analysis was carried out to investigate the mode of rupture in Fig. 10b. The absence of fibrous and dimpled network and the presence of cleavage planes in the fractography suggested that the mode of failure was brittle. 

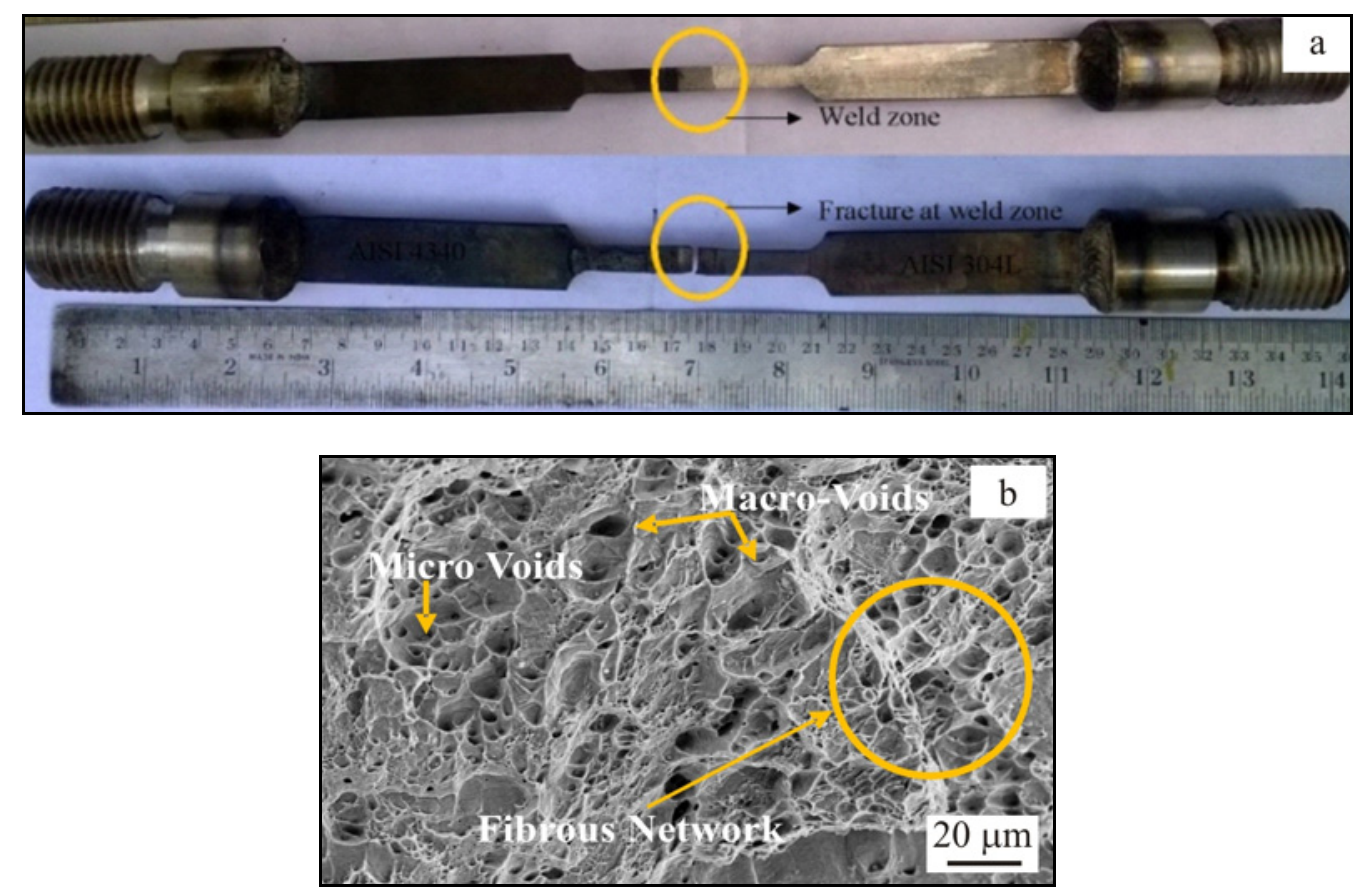

Fig. 9. (a) High-temperature tensile studies on the dissimilar weldments of AISI 4340 and AISI 304L before and after fracture; (b) SEM fractography of the high temperature tensile tested weldment.
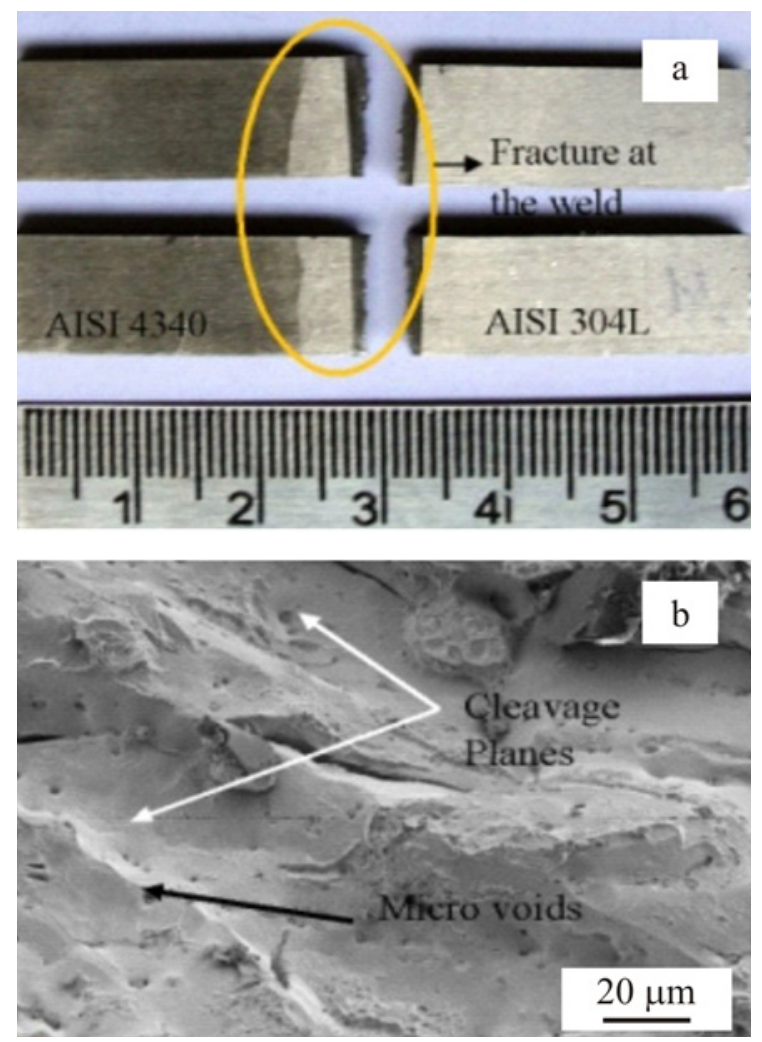

Fig. 10. (a) Impact tested samples of dissimilar weldments (b); SEM fractography of the impact tested sample.

In a nutshell, this study envisaged that PCGTA welding of AISI 4340 and AISI 304L offered good ten- sile properties at room temperature conditions as compared to the results reported by Ozdemir et al. [18, 19]. Weld metal cracking was not observed, which resulted as a consequence of the PCGTA welding and pre-heating of AISI 4340.

\section{Conclusions}

This study reported the joining of AISI 4340 and AISI 304L by PCGTA welding technique without the aid of filler wire. The following are the major conclusions summarized from the present study:

(a) Defect free welds of AISI 4340 and AISI 304L could be obtained from PCGTA welding process without filler metal.

(b) Microstructure revealed the presence of martensite at the weld zone and the HAZ of AISI 4340 with dispersed carbides.

(c) Tensile failures occurred at the parent metal of AISI 304L in all the trials at room temperature. The results showed that weld strength is higher as compared to the parent metals employed in the study.

(d) Elevated temperature tensile studies showed enhanced rate of void formation and increased dislocation mobility, which in turn resulted in reduced tensile strength of this dissimilar weld joint.

(e) Lower impact toughness of these dissimilar weldments could be related to the higher hardness, exhibited due to the presence of high carbon martensite with finely dispersed carbides.

(f) Although the weld zone impact toughness of 
this dissimilar weldment is lower, the room temperature tensile strength of the weld joint is found to be satisfactory.

(g) The study recommends autogenous welding technique which is cost effective, for joining these dissimilar metals in applications which are not subjected to impact loading.

\section{Acknowledgements}

The authors sincerely thank the Aeronautical Research and Development Board (AR\&DB), India for providing the financial aid towards this research work. Also, the authors convey their sincere thanks to the Department of Science and Technology-FIST for establishing the Instron facility to our VIT University.

\section{References}

[1] ASM Handbook: Properties and Selection: Irons, Steels and High-performance Alloys. Materials Park, ASM International 2002.

[2] Welding Handbook: Welding processes. Miami, American Welding Society 1991.

[3] ASM Handbook: Welding Brazing and soldering. Ohio, ASM International 1993.

[4] Lippold, J. C., Kotecki, D. J.: Welding Metallurgy and Weldability of Stainless Steels. New Jersey, John Wiley \& Sons 2005.

[5] Tomita, Y.: Mat. Sci. Tech., 7, 1991, p. 481. doi:10.1179/mst.1991.7.6.481

[6] Viswanathan, R., Hudak, S. J.: Metall. Trans. A, 8, 1977, p. 1633. doi:10.1007/BF02644870

[7] Aerospace Structural Meals Handbook. Massachusetts, Department of Defense Mechanics Research Center Watertown 1979.

[8] Arivazhagan, N., Surendra, S., Satya, P., Reddy, G. M.: Mater. Des., 32, 2011, p. 3036. doi:10.1016/j.matdes.2011.01.037

[9] Wyatt, L. M.: Materials of Construction for Steam Power Plants. London, Applied Science Publishers 1976.

[10] Smith, R. E., Hanford, R., Cheng, S. C.: Nucl. Eng. Des., 124, 1990, p. 79. doi:10.1016/0029-5493(90)90354-Z

[11] Shushan, S. M., Charles, A., Congleton, I.: Corros. Sci., 38, 1996, p. 673. doi:10.1016/0010-938X(96)00158-8

[12] Joseph, A., Rai, S. K., Jayakumar, T., Murugan, N.: Int. J. Press. Vessels. Pip., 82, 2005, p. 700. doi:10.1016/j.ijpvp.2005.03.006
[13] Arivazhagan, N., Singh. S., Prakash, S., Reddy, G. M.: Int. J. Adv. Manuf. Technol., 39, 2008, 679 doi:10.1007/s00170-007-1266-7

[14] Jafarzadegan, M., Feng, A. H., Abdollah-Zadeh, A., Saeid, T., Shen, J., Assadi, H.: Mater. Charact., 74, 2012, p. 28. doi:10.1016/j.matchar.2012.09.004

[15] Eghlimi, A., Shamanian, M., Raeissi, K.: Surf. Coat. Tech., 244, 2014, p. 45. doi:10.1016/i.surfcoat.2014.01.047

[16] Pal, K., Pal, K. S.: J. Mater. Eng. Perform., 20, 2011, p. 918. doi:10.1007/s11665-010-9717-y

[17] Tseng, K. H., Chou, C. P.: J. Mater. Process. Tech., 123, 2002, p. 346. doi:10.1016/S0924-0136(02)00004-3

[18] Ozdemir, N.: Mater. Lett., 59, 2005, p. 2504. doi:10.1016/j.matlet.2005.03.034

[19] Ozdemir, N., Sarsilmaz, F, Hascalik, A.: Mater. Des., 28, 2007, p. 301. doi:10.1016/j.matdes.2005.06.011

[20] Arivazhagan, N., Surendra, S., Satya, P., Reddy, G. M.: Mater. Des., 32, 2011, p. 3036 doi:10.1016/j.matdes.2011.01.037

[21] Hascalik, A., Unal, E., Ozdemir, N.: J. Mater. Sci., 41, 2006, p. 3233. doi:10.1007/s10853-005-5478-7

[22] Ananthapadmanaban, D., Seshagiri, R. V., Nikhil, A., Prasad, R. K.: Mater. Des., 30, 2009, p. 2642. doi:10.1016/j.matdes.2008.10.030

[23] Hajiannia, I., Shamanian, M., Kasiri, M.: Mater. Des. 50, 2013, p. 566. doi:10.1016/j.matdes.2013.03.029

[24] Mohandas, T., Reddy, G. M.: J. Mater. Process. Technol., 69, 1997, p. 222. doi:10.1016/S0924-0136(97)00022-8

[25] Farahani, F., Shamanian, H., Ashrafizadeh, A.: AMAE Int. J. Manuf. Mater. Sci., 2, 2012, p. 1.

[26] Giridharan, P. K., Murugan, N.: Int. J. Adv. Manuf. Technol., 40, 2009, p. 478. doi:10.1007/s00170-008-1373-0

[27] Brooks, J. A., Thompson, A. W., Williams, C.: Welding Journal, 63, 1984, p. 171.

[28] Arivazhagan, N., Narayanan, S., Surendra, S., Satya, P., Reddy, G. M.: Mater. Des., 34, 2012, p. 459 doi:10.1016/j.matdes.2011.08.034

[29] Campbell, F. C.: Elements of Metallurgy and Engineering Alloys. Ohio, ASM International 2012.

[30] Abe, F., Kern, T. U., Viswanathan, R.: Creep Resistant Steels. Cambridge, Woodhead Publishing 2008.

[31] Francis, J. A., Cantin, G. M. D., Mazur, W., Bhadeshia, H. K. D. H.: Sci. Technol. Weld J., 14, 2009 p. 436. doi:10.1179/136217109X415884

[32] Giroux, P. F., Dalle, F., Sauzay, M., Malaplate, J., Fournier, B., Gourgues-Lorenzon, A. F.: Mater. Sci. Eng. A, 527, 2010, p. 3984. doi:10.1016/j.msea.2010.03.001 